\title{
Frequency and Outcomes of Early Onset Seizures after Ischemic Stroke
}

\author{
Sai Sampath Kumar Natuva*, Bala Khaseem D, Ravi Kiran Padala, Sunanda T and Ganesh Vallampalli \\ Department of Neurology, Narayana Medical College, Nellore, Andhra Pradesh, India
}

"Correspondence to:

Sai Sampath Kumar Natuva, DM

Department of Neurology

Narayana Medical College, Nellore 524003

Andhra Pradesh, India

E-mail: drnssampath123@gmail.com

Received: October 16, 2015

Accepted: January 25, 2016

Published: January 28, 2016

Citation: Natuva SSN, Khaseem BD, Padala RK, Sunanda T, Vallampalli G. 2016. Frequency and Outcomes of Early Onset Seizures after Ischemic Stroke.J Neurol Exp Neurosci 1(2): 30-33.

Copyright: (C) 2016 Natuva et al. This is an Open Access article distributed under the terms of the Creative Commons Attribution 4.0 International License (CC-BY) (http://creativecommons. org/licenses/by/4.0/) which permits commercial use, including reproduction, adaptation, and distribution of the article provided the original author and source are credited.

Published by United Scientific Group

\begin{abstract}
Introduction: Stroke is most common cause of new onset seizures in elderly. In this study, we assessed frequency and outcome by National Institute of Health Stroke Scale (NIHSS) and modified Rankin Scale (mRS) in early onset seizures after ischemic stroke.
\end{abstract}

Methods: Case records of all patients during period of June 2013-June 2014 from indigenously made stroke registry of Narayana medical college \& Hospital were reviewed. Only cases with early onset of seizures ( $<14$ days) after ischemic stroke were included as cases (14/304), remaining ischemic stroke patients without seizures are enrolled as controls (290/304). We recorded morbidity, mortality, length of hospital stay, NIHSS and mRS scores from the available data.

Results: A total of 304 case records of stroke patients were analysed. Mean age of patients was $53.62 \pm 13.06$ years (20-85). Frequency of early onset seizures seen in $14(4.6 \%)$ patients. Types of seizures observed in these patients are Generalised tonic clonic seizuresw-6, Focal seizures-5, Epilepsia Partialis Continua-2 and Complex Partial Seizures-1. 12 patients had cortical infarcts while remaining 2 had sub cortical infarcts. Phenytoin and Oxcarbamazepine were preferred drugs even though more than $50 \%$ had partial seizures in one or other form. During the follow up, recurrent seizure or mortality was not observed. No statistically significant difference in duration of hospital stay, NIHSS and $\mathrm{mRS}$ score at admission and at discharge between patients with and without seizures.

Conclusion: Even though we followed for a short period of one year we observed a sizeable proportion (4.6\% of 304) of ischemic stroke cases with early onset seizures. On other hand, stroke severity has no influence on seizures or seizures have no influence on functional outcome.

\section{Keywords} Outcome

Early onset seizures, Seizure frequency, Seizures after ischemic stroke,

\section{Introduction}

Stroke is the most commonly identified cause of epilepsy in adult populations older than 35 years. In the elderly, stroke accounts for more than half of the newly diagnosed cases of epilepsy in which a cause is determined, ahead of degenerative disorders, brain tumours, and head trauma [1]. From stroke registry data, about $5 \%$ to $20 \%$ of all individuals who have a stroke will have subsequent seizures. Seizures may be a more common accompaniment of hemorrhagic rather than ischemic stroke [2]. Due to the fact that ischemic strokes are far more frequent 
than hemorrhagic ones, the majority of stroke-related epileptic insults are due to cerebral infarction [3-6]. Post-stroke seizure is defined as "single or multiple convulsive episode/s (fit/s) after stroke and thought to be related to reversible or irreversible cerebral damage due to stroke regardless of time of onset following the stroke" [7]. The risk factors and incidence of seizures after stroke vary widely. Stroke subtype, location, and severity being the common risk factors for post stroke seizure patients. Post stroke seizure rates are highest in those with intraparenchymal haemorrhage and large supratentorial ischemic strokes, and lowest after transient ischemic attacks, lacunar infarcts, and brainstem strokes [2, 8]. Despite the relatively low incidence of epilepsy after cerebral stroke, post stroke epilepsy is one of the most common causes of epilepsy due to the high incidence of stroke [9]. To this purpose, we estimated the frequency and functional outcomes of early onset seizures after ischemic stroke from stroke registry during a 12 month period.

\section{Methods}

This retrospective study was conducted in the department of neurology at Narayana Medical College, Nellore. Institute Ethical committee approved the study protocol. Case records of all patients during the period June 2013-June 2014 from the indigenously made stroke registry of Narayana medical college \& Hospital were reviewed. Data was extracted from case record forms which include age, gender, medical history and medication usage, time and type of the seizures after stroke, CT scan and MRI scan reports OCSP classification was applied to the cases. Only those cases with early onset of seizures ( $<14$ days) after ischemic stroke were included based on clinic neurological examination and EEG findings. Cases were excluded if they were below 18 years, or known patient of epilepsy or late onset seizures (>14 days) after stroke, or late presentation to hospital or hemorrhagic stroke, or head injury or who underwent cranial surgery or having gliosis or Neuro-infections or intracranial space occupying lesions. Morbidity, mortality, length of hospital stay and functional outcomes as assessed by National Institute of Health Stroke Scale (NIHSS) and modified Rankin Scale (mRS).

\section{Statistical Analysis}

The data was entered in case record forms as a source document and transfer to Microsoft excel Spread sheet 2007 (version 2007, Microsoft Corp, Seattle, Washington). Statistical analysis was performed using SPSS-16. Descriptive results are presented as mean and standard deviation (SD) and category data as actual numbers and percentages. Unpaired $t$ test was used to the significance of differences between two groups on continuous variables. A two tailed $p$ value of less than 0.05 was considered statistically significant.

\section{Results}

A total of 304 case records of stroke patients were analysed. The mean age of the patients was $53.62 \pm 13.06$ years $(20-85)$. In our study, early onset seizures (with-in 14 days of stroke onset) were seen in 14 (4.6\%) of patients. The mean duration of occurrence of early onset seizure was $1.0 \pm 0.48$ days. There were 11 males and 3 females. The mean age was $55.3( \pm 1.67)$ years. Various risk factors in ischemic stroke patients with seizures and without seizures were noted and the statistical significance was analyzed [Table 1]. The risk factors that these patients were having includes hypertension in 9 patients, diabetes in 8 patients, dyslipidemia in 8 patients, coronary artery disease in 1 patient [Table 1]. From the data outlined in Table 1 it was evident that the major risk factor for seizures after stroke is the presence of cortical infarct. Diabetes mellitus in ischemic stroke patients also found to be significant risk factor for seizures causation. Different types of seizures which were observed in these patients were as follows Generalised tonic clonic seizures -6, Focal-5, EPC-2 and CPS-1. Out of 14 patients 7 patients had right hemispheric and remaining

Table 1: Risk factors in ischemic stroke patients with seizures and without seizures.

\begin{tabular}{|c|c|c|c|}
\hline Risk Factors & $\begin{array}{c}\text { No of PTs } \\
\text { (seizures) } \mathbf{n = 1 4}\end{array}$ & $\begin{array}{c}\text { No of PTs (without } \\
\text { seizures) } \mathbf{n = 2 9 0}\end{array}$ & P value \\
\hline HTN & 9 & 196 & 0.797 \\
\hline Dyslipidemia & 8 & 115 & 0.193 \\
\hline DM & 8 & 86 & 0.03 \\
\hline CAD & 1 & 12 & 0.587 \\
\hline AF & 1 & 7 & 0.280 \\
\hline CRHD & 1 & 5 & 0.156 \\
\hline Smoker & 9 & 162 & 0.535 \\
\hline Alcoholic & 8 & 133 & 0.408 \\
\hline Cortical Infarct & 12 & 28 & $<0.0001$ \\
\hline NIHSS $\geq 11$ & 8 & 127 & 0.326 \\
\hline BI $\leq 46$ & 8 & 142 & 0.55 \\
\hline
\end{tabular}

7 patients had left hemispheric infarcts. Arterial territory distribution revealed that 2 patients had anterior cerebral artery infarct, 11 patients had middle cerebral artery infarct and one patient had infarct in posterior circulation. According to OCSP classification 11 patients had partial anterior circulation infarcts (PACI), 2 had lacunar infarcts (LACI) and one had posterior circulation infarct (POCI). 12 patients had cortical infarcts while the remaining 2 had sub cortical infarcts. One patient had epilepsia partialis continua which lasted for 6 hours. In another patient with GTCS, we observed recurrence of four episodes of seizures in one week duration. Remaining all other patients had at least one episode of seizure. All these patients were treated with either phenytoin or levetiracetam or oxcarbamazepine or combination of these drugs. 3 patients received three drugs, 2 patients received two drugs and 9 patients received single drug [Table 2]. Oxcarbamazepine was preferred in most of these seizure patients because of $50 \%$ had partial seizures in one or other form. One patient with GTCS had gone into renal failure due to sepsis following aspiration and was managed conservatively with phenytoin. Follow up records of these patients were available for three months only, during this period neither recurrent seizure nor mortality was observed. The clinical characteristics, functional outcomes 
Table 2: Clinical characteristics of patients with early onset seizures after ischemic stroke.

\begin{tabular}{|c|c|c|c|c|c|c|c|c|c|c|c|c|c|c|}
\hline Patient & 1 & 2 & 3 & 4 & 5 & 6 & 7 & 8 & 9 & 10 & 11 & 12 & 13 & 14 \\
\hline Age (yrs) & 71 & 29 & 42 & 56 & 30 & 46 & 48 & 60 & 62 & 60 & 50 & 60 & 52 & 85 \\
\hline Gender & M & M & $\mathrm{M}$ & $\mathrm{M}$ & $\mathrm{M}$ & M & $\mathrm{M}$ & M & $\mathrm{M}$ & $\mathrm{F}$ & $\mathrm{M}$ & $\mathrm{M}$ & F & $\mathrm{M}$ \\
\hline $\begin{array}{l}\text { Seizure after } \\
\text { stroke (days) }\end{array}$ & 2 & 1 & 0.5 & 2 & 1 & 1 & 1 & 0.5 & 1 & 1 & 1 & 1 & 1 & 1 \\
\hline $\begin{array}{l}\text { Type of } \\
\text { seizure }\end{array}$ & GTCS & GTCS & Focal & Focal & GTCS & CPS & EPC & Focal & GTCS & GTCS & GTCS & CPS & Focal & Focal \\
\hline $\begin{array}{c}\text { Frequency of } \\
\text { occurrence }\end{array}$ & 1 & 1 & 1 & 1 & 1 & & $\begin{array}{c}\text { One } \\
\text { episode } \\
\text { lasted for } \\
6 \text { hours }\end{array}$ & $\begin{array}{l}3 \text { episodes } \\
\text { over } \\
24 \text { hours }\end{array}$ & $\begin{array}{l}4 \text { episodes } \\
\text { in one wk }\end{array}$ & 1 & 1 & & $\begin{array}{l}3 \text { episodes } \\
\text { over } 3 \\
\text { days }\end{array}$ & 1 \\
\hline $\begin{array}{c}\text { Hospital stay } \\
\text { (days) }\end{array}$ & 7 & 7 & 5 & 3 & 10 & 16 & 7 & 6 & 5 & 3 & 7 & 8 & 6 & 8 \\
\hline $\begin{array}{l}\text { NIHSS @ } \\
\text { Admission }\end{array}$ & 17 & 22 & 5 & 26 & 28 & 15 & 6 & 3 & 6 & 28 & 26 & 5 & 4 & 8 \\
\hline $\begin{array}{l}\text { NIHSS @ } \\
\text { Discharge }\end{array}$ & 29 & 14 & 2 & 20 & 22 & 12 & 3 & 2 & 4 & 23 & 16 & 3 & 2 & 6 \\
\hline $\begin{array}{c}\text { mRS @ } \\
\text { Admission }\end{array}$ & 5 & 5 & 3 & 5 & 5 & 5 & 4 & 3 & 3 & 5 & 5 & 3 & 2 & 4 \\
\hline $\begin{array}{c}\text { mRS @ } \\
\text { Discharge }\end{array}$ & 5 & 4 & 2 & 5 & 4 & 4 & 3 & 2 & 2 & 5 & 4 & 2 & 1 & 3 \\
\hline OCSP & PACI & PACI & PACI & PACI & PACI & PACI & PACI & PACI & LACI & LACI & POCI & PACI & PACI & PACI \\
\hline Involvement & $\begin{array}{c}\text { Sub } \\
\text { Cortical }\end{array}$ & Cortical & Cortical & Cortical & $\begin{array}{l}\text { Sub } \\
\text { cortical }\end{array}$ & Cortical & Cortical & Cortical & Cortical & Cortical & Cortical & Cortical & Cortical & Cortical \\
\hline Drug Use & $3(\mathrm{P}, \mathrm{L}, \mathrm{O})$ & $2(\mathrm{P}, \mathrm{L})$ & $1(\mathrm{O})$ & $1(\mathrm{O})$ & 3(P,L,O) & $1(\mathrm{O})$ & 3(O,L.P) & $2(\mathrm{O}, \mathrm{L})$ & $1(\mathrm{P})$ & $1(\mathrm{p})$ & $1(\mathrm{P})$ & $1(\mathrm{O})$ & $1(\mathrm{O})$ & $1(\mathrm{O})$ \\
\hline
\end{tabular}

$\mathrm{P}$ - Phenytoin, L- Levetiracetam, O - Oxcarbazepine

OCSP: Oxfordshire community stroke project.

Partial Anterior Circulation Infarcts (PACI), Lacunar Circulation Infarcts (LACI).

and duration of hospital stay were shown in Table 2 and 3. There was no statistically significant difference in duration of hospital stay, NIHSS and mRS score at admission and at discharge between patients with and without seizures. Eight (57\%) of our patients NIHSS score at admission were more than 15 suggesting severe disability.

Table 3: Functional outcomes and length of hospital stay in patients with early onset seizures and without seizures.

\begin{tabular}{|c|c|c|c|}
\hline Stroke Patients & EOS (n= 14) & $\begin{array}{c}\text { No Seizure } \\
(\mathbf{n}=\mathbf{2 9 0})\end{array}$ & P value \\
\hline \multicolumn{4}{|c|}{ Admission } \\
\hline NIHSS & $13.44 \pm 9.08$ & $10.67 \pm 6.3$ & $\mathrm{p}>0.05$ \\
\hline $\mathrm{mRS}$ & $4.00 \pm 1.00$ & $3.7 \pm 1.1$ & $\mathrm{p}>0.05$ \\
\hline \multicolumn{4}{|c|}{ Discharge } \\
\hline NIHSS & $10.18 \pm 8.62$ & $7.3 \pm 5.24$ & $\mathrm{p}>0.05$ \\
\hline mRS & $3.12 \pm 1.23$ & $2.8 \pm 1.0$ & $\mathrm{p}>0.05$ \\
\hline $\begin{array}{c}\text { Duration of hospital stay } \\
\text { (days) }\end{array}$ & $6.90 \pm 4.93$ & $6.85 \pm 4.73$ & $\mathrm{p}>0.05$ \\
\hline \multicolumn{4}{|c|}{ EOS - Early Onset seizures } \\
\hline
\end{tabular}

\section{Discussion}

The incidence of early onset seizures in post stroke patients varies from 1.8-15\%. Most early-onset seizures occur during the first 1 to 2 days after ischemia. We observed that $4.6 \%$ of our patients had an episode of seizures within 24 hours of onset of stroke. Camilo et al. [10], found that the estimates of early post ischemic stroke seizures were as $2 \%$ while Lamy et al. [11], observed seizures in $2.4 \%$ of 581 cryptogenic stroke patients within the first 24 hours. Dhanuka et al. [9], observed that the incidence of post-stroke epilepsy in India was 13\%. Bladin et al. [2], found the incidence of seizures to be $8.6 \%$ among 1632 with ischemic stroke and $43 \%$ of these patients experienced a seizure within the first 24 hours after stroke. In a series restricted to early-onset seizures, $90 \%$ had ictal activity within the first 24 hours [12]. Our patients have co morbidities such as Hypertension, Diabetes, Hyperlipidemia etc., one or more of such metabolic and physiologic derangements could be responsible for seizures in these patients. The presence of diabetes mellitus in ischemic stroke patients was observed to be having significant association with the manifestation of seizures in our study. Approximately 50\% to $90 \%$ of early onset seizures appear to be simple partial seizures $[2,11,13$, 14]. Various studies revealed simple partial seizures as the most common type $(61 \%)$ in patients with early onset seizures 
$[12,14,15]$. One study reported a higher frequency (50\%) of generalized tonic-clonic seizures without focal onset in patients with early-onset seizures [16]. The recommended first line AEDs for both focal seizures and generalised seizures are carbamazepine, lamotrigine, sodium valproate, and topiramate whereas phenytoin, phenobarbital, and clonazepam are the alternative AED's. We prescribed phenytoin as the first line of AED in acute Neuro ICU setting for patients of stroke with early onset seizure because of the ease of parenteral administration and cost effectiveness, even though more than $50 \%$ had partial seizures in one or other form and oxcarbamazepine as an additional drug. Julian et al. [17] found that NIHSS score was significantly higher in patients with seizures $(7.7 \pm 6.1)$, than in patients without seizures $(4.3 \pm$ 4.9). In our study we didn't find any statistical significance in NIHSS score in stroke patients with or without early onset seizures. Even though $57 \%$ of our patients NIHSS score at admission were more than 15 suggesting severe disability. One of the possible explanations includes that a single seizure may not be severe enough to disrupt the neuronal integrity and physiology, to produce irreversible damage. It is possible that prolonged seizures or recurrent seizures may produce irreversible damage to the brain which may result in poor functional outcomes. However, we didn't find poor outcomes in one patient with epilepsia partialis continua which lasted for 6 hours and another patient with GTCS, who had recurrence of four episodes of seizures in one week. Early onset seizure doesn't show any difference on the NIHSS and mRS scores at discharge when compared to non seizure ischemic stroke patients suggesting that neither severity of stroke has any influence on seizures nor seizures have any influence on the functional outcomes. Though cortical infarcts are described as risk factor for seizure, we consider finding more number of cortical infarcts in the group of ischemic stroke patients with seizures is mere coincidental rather than causative in the study; many other comorbid factors like metabolic disturbances (hyperglycemia) could have also been involved in the causation of seizures which were not completely evaluated in our study. This is one of the limitations in our study. One should be vigilant in interpreting this study results as the data was collected from one year stroke registry which may result in an underestimate of frequency of early onset seizures. Additionally, late onset seizures couldn't be recorded as the data available in 3 months following the stroke.

\section{Conclusions}

Even though we followed for a shorter period of one year we observed a sizeable proportion (4.6\% of 304) of ischemic stroke cases with early onset seizures. On the other hand, neither severity of stroke has any influence on seizures nor seizures have any influence on the functional outcomes.

\section{References}

1. Hauser WA, Annegers JF, Kurland LT. 1993. Incidence of epilepsy and unprovoked seizures in Rochester, Minnesota: 1935-1984. Epilepsia 34(3): 453-468. doi: 10.1111/j.1528-1157.1993.tb02586.x

2. Bladin CF, Alexandrov AV, Bellavance A, Bornstein N, Chambers B, et al. 2000. Seizures after stroke: a prospective multicenter study. Arch Neurol 57(11): 1617-1622. doi: 10.1001/archneur.57.11.1617

3. De Reuck J, Vanhee F, Van Maele G, Claeys I. 2007. Magnetic resonance imaging after seizures in patients with an ischemic stroke. Cerebrovasc Dis 23(5-6): 339-343. doi:10.1159/000099132

4. De Reuck J, Proot P, Van Maele G.2007. Chronic obstructive pulmonary disease as a risk factor for stroke-related seizures. Eur J Neurol 14(9): 989-992. doi: 10.1111/j.1468-1331.2007.01829.x

5. De Reuck J, Nagy E, Van Maele G. 2007. Seizures and epilepsy in patients with lacunar strokes. J Neurol Sci 263(1-2): 75-78. doi: 10.1016/j.jns.2007.06.004

6. De Reuck J, Hemelsoet D, Van Maele G. 2007. Seizures and epilepsy in patients with a spontaneous intracerebral haematoma. Clin Neurol Neurosurg 109(6): 501-504. doi: 10.1016/j.clineuro.2007.04.001

7. Myint PK, Staufenberg EFA, Sabanathan K. 2006. Post-stroke seizure and post-stroke epilepsy. Postgrad Med J 82(971): 568-572. doi: 10.1136/pgmj.2005.041426

8. So EL, Annegers JF, Hauser WA, O'Brien PC, Whisnant JP. 1996. Population-based study of seizure disorders after cerebral infarction. Neurology 46(2): 350-355. doi: 10.1212/WNL.46.2.350

9. Dhanuka AK, Misra UK, Kalita J. 2001. Seizures after stroke: a prospective clinical study. Neurol India 49(1): 33-36.

10. Camilo O, Goldstein LB. 2004. Seizures and epilepsy after ischemic stroke. Stroke 35(7): 1769-1775. doi: 10.1161/01. STR.0000130989.17100.96

11. Lamy C, Domigo V, Semah F, Arquizan C, Trystram D, et al. 2003. Early and late seizures after cryptogenic ischemic stroke in young adults. Neurology 60(3): 400-404.

12. Gupta SR, Naheedy MH, Elias D, Rubino FA. 1988. Postinfarction seizures. A clinical study. Stroke 19(12): 1477-1481. doi: 10.1161/01. STR.19.12.1477

13. Kilpatrick CJ, Davis SM, Tress BM, Rossiter SC, Hopper JL, et al. 1990. Epileptic seizures in acute stroke. Arch Neurol 47(2): 157-160. doi:10.1001/archneur.1990.00530020053014

14. Giroud M, Gras P, Fayolle H, Andre N, Soichot P, et al. 1994. Early seizures after acute stroke: a study of 1640 cases. Epilepsia 35(5): 959964. doi: 10.1111/j.1528-1157.1994.tb02540.x

15. Dávalos A, de Cendra E, Molins A, Ferrandiz M, Lopez-Pousa S, et al. 1992. Epileptic seizures at the onset of stroke. Cerebrovasc Dis 2: 327331. doi: $10.1159 / 000109039$

16. Arboix A, Comes E, Massons J, Garcia-Eroles L, Massons JB, et al. 2003. Prognostic value of very early seizures for in-hospital mortality in atherothrombotic infarction. Eur Neurol 50(2): 78-84. doi:10.1159/000072503

17. Conrad J, Pawlowski M, Dogan M, Kovac S, Ritter MA, et al. 2013. Seizures after cerebrovascular events: Risk factors and clinical features. Seizure 22(4): 275-282. doi: 10.1016/j.seizure.2013.01.014 